\title{
Multi-level screening of computation-ready, experimental metal-organic frameworks for natural gas purification
}

\author{
Zhi $\mathrm{Li}^{1}$, Yue Zhang ${ }^{1}$, Bei $\mathrm{Liu}^{2}$, and Guangjin $\mathrm{Chen}^{2}$ \\ ${ }^{1}$ Qilu University of Technology \\ ${ }^{2}$ China University of Petroleum Beijing
}

October 8, 2020

\begin{abstract}
In this work, traditional Monte Carlo simulation and DFT-based structural optimization methods were combined to screen computation-ready experimental MOF database for the application of natural gas purification. Our results show that about half of the good performing CoRE-MOF structures displayed various degrees of deformation (even collapse) after the structure optimization. This phenomenon attributed to the strong attraction of unsaturated metals which attract nearby organic components. For some materials with deformation, unsaturated metals form new bonds with the adjacent organic linkers creating distortions that would be unrealistic in the experimental materials. For the remaining relatively stable materials whose structural characteristics did not change too much, we further studied the adsorption performance of their optimized structures. Finally, 12 good-performing MOF materials with high stability were screened out which could greatly improve the possibility for constructing robust MOFs that could hold open metal sites by experiments.
\end{abstract}

\section{Hosted file}

Manuscript.pdf available at https://authorea.com/users/365557/articles/485597-multi-levelscreening-of-computation-ready-experimental-metal-organic-frameworks-for-natural-gaspurification 